\title{
MICROSTRIP EMITTING MODULE FOR TRANSCEIVING X-BAND AESA
}

\author{
Anatoly A. Genov, Vladislav V. Osipov \\ Moscow Aviation Institute (National Research University), https://mai.ru \\ Moscow 125993, Russian Federation
}

\begin{abstract}
Andrey V. Gurkovsky, Denis N. Velichko
Corporation of Space Systems of Special Purpose "Comet", http://corpkometa.ru

Moscow 115280, Russian Federation

kt-mati@mail.ru,ovv_42@mail.ru,decto4134@mail.ru,godfather.denis90@gmail.com
\end{abstract}

Abstract. This article discusses the development of a microstrip radiating X-band module for the transceiving space-based active electronically scanning array (AESA). The result of electrodynamic modeling of the emmiting module in CST Studio Suite environment is presented. Design features of multilayer patch emitter are considered. A comparative analysis of the calculated and measured characteristics of the emitting module is given.

Keywords: active electronically scanned array, microstrip radiating module

УАК 621.396.67

Bibliography - 9 references

Received 18.05.2018

RENSIT, 2018, 10(1):31-34

DOI: $10.17725 /$ rensit.2018.10.031

\section{Contents}

1. Introduction (31)

2. The development of the radiating module (31)

3. Comparative analysis (33)

4. Conclusion (34)

References (34)

\section{INTRODUCTION}

Nowadays there is a growing relevance of using the phased array in military and civilian spacecrafts. One of the components of AESA is the transceiving modules (TM), from which the antenna array is formed [1].

The development task of an emitting element for the TM is rather complex because of the strict requirements to construction whose must provide stability to dynamic loads and external actions of outer space. Also there is the restriction on the weight and size of the TM. Because of the emitting element operation on two spased frequency ranges, the emitting element must be wide-band and matched to two frequency ranges: the one is for receiving and the other is for transmitting.

The aim of this work is the implementation of the electrodynamic model of the emitting element [2], which calculated in the CST Studio Suite, the experimental test of its electrodynamic characteristics and the comparison of the results of the measured characteristics with the calculated ones.

\section{THE DEVELOPMENT OF THE RADIATING MODULE}

Considering the various options for the manufacture of the emitting modules, the choice was made in favor of plainmicrostrip emitters. Due to the possibility of using printing technology in the manufacture of multi-layer structure high repeatability appears in the production of the proposed design. Also, thin metallization layers $(18 \mu \mathrm{m})$ on the composite polytetrafluorumethylene (PTFE) laminate of Rogers (USA) material allow to gain significantly in the weight of the final design of the emitting module.

In the future, when using the radiating module in the array, the plain antenna array will distribute the load more evenly in regard to complex emitters consisting of threedimensional structures made in the form of horns, cones or vibrators. Also in this case it is easier to implement protection from the 
impact of meteor and man-caused particles and radiation resistance of a plain antenna arraysubject to weight restrictions.

In the large variety of plainmicrostrip emitters the slit emitter was taken as the basis. Because maintaining the uniformity of the frequency matching on two ranges is a difficult task, this type of emitter allows to approach more flexible to the issue of matching $[3,4]$.

The power supply of the emitting module must be from a 50-Ohms coaxial line. In order to reduce the weight and sizedimensions of the power supply of the emitting module must be from one port. The SMA connector is soldered to the microstrip of its central line, and the connector case - to the ground (shield). The width of the microstrip is calculated for matching at $50 \mathrm{Ohms}$ [5]. The shield is made in the form of a $0.5 \mathrm{~mm}$ thick copper plate.

Microstrip line excites the slit located above it. The slit is etched in the upper metallized copper layer $(18 \mu \mathrm{m})$ Rogers $4350 \mathrm{~B}$ (Fig. 1a), and the microstrip in the lower metallized copper layer (Fig. 1b). The slit is made in the form of narrow perpendicular rectangular holes. Changing the geometrical dimensions of the slit, it is possible to achieve the resonance in the required frequency range $[6,7]$. For an ideal antenna dielectric between the microstrip and the slit is the air with a dielectric constant of $\varepsilon=1$, but due to the fact that it is possible to produce thin microstrip lines only using a substrate, we have chosen a laminate from composite

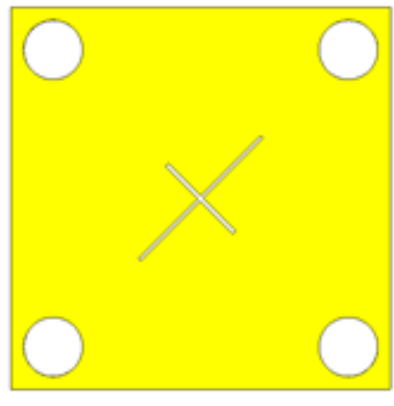

$a$

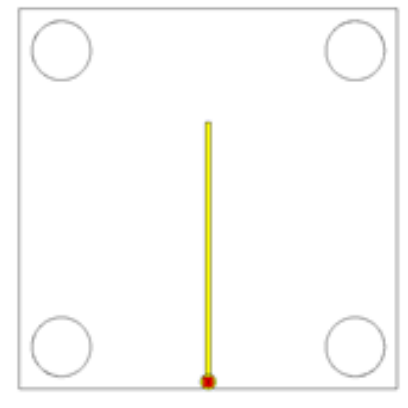

$b$
Fig. 1. The layer Rogers $4350 B$ with microstrip and the slit: a) top view b) bottom view.
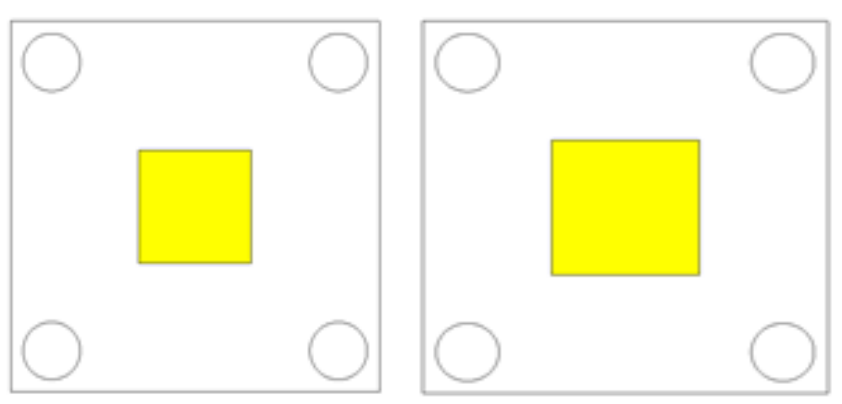

Fig. 2. Layer Rogers 4350B with first patch (left), second patch (right).

PTFE material Rogers $4350 \mathrm{~B}$ for this task. Based on the fact that Rogers $4350 \mathrm{~B} \varepsilon=3.48$, the height of the layer Rogers $4350 \mathrm{~B}$ was chosen $0.338 \mathrm{~mm}$.

Two square patches, etched in the metallic copper layers of Rogers 4350B, are used for the enhancement the resonance on two frequency ranges. The first patch - «parasitic»- is necessary to expand the matching in the frequency domain of the second patch. The size of the first patch is $11.4 \mathrm{~mm}$ (Fig. 2, left), it is etched on the upper metallized Rogers layer and the second patch on the lower layer. The size of the second patch is $13.6 \mathrm{~mm}$ (Fig. 2, right) [8].

The holes are made on the edges in all four layers to withstand the distance and plane of the layers by using plastic pins and washers of different sizes. Fig. 3 shows all the layers of the emitting module with a side view. The distance between the ground layer-1 and the Rogers layer with a microstrip and a slit-2 is $1.5 \mathrm{~mm}$. The distance between layer 2 and layer 3 (Rogers with the first patch) is $0.5 \mathrm{~mm}$. The distance between layer 3 and layer 4 (Rogers with the second patch) is $1.5 \mathrm{~mm}$. The size of all layers of the emitting module is $37.4 \times 37.4$ $\mathrm{mm}$.

In the software environment CST Studio Suite an electrodynamic model of the emitting module was built and calculated, on the basis of which the following electrical and technical

Fig. 3. Layer of the emitting module - side view. 


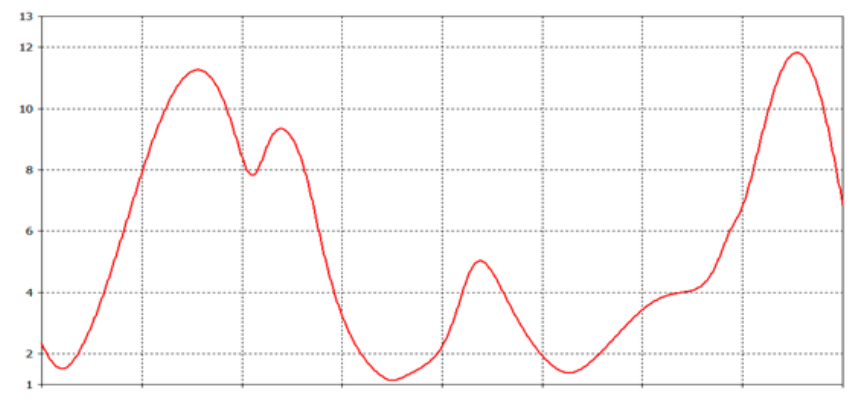

Fig. 4. Graph of SWR versus frequency in the range from 5 to $9 \mathrm{GH}$ :

characteristics were obtained: standing wave ratio (SWR), gain constant, polar pattern.

Fig. 4 shows a graph of SWR versus frequency in the range from 5 to $9 \mathrm{GHz}$.

Fig. 5 shows the polar pattern of the model of the emitting module with a gain constant of $8.2 \mathrm{~dB}$. The width of the polar pattern (at $-3 \mathrm{~dB}$ ) is $71.3^{\circ}$.

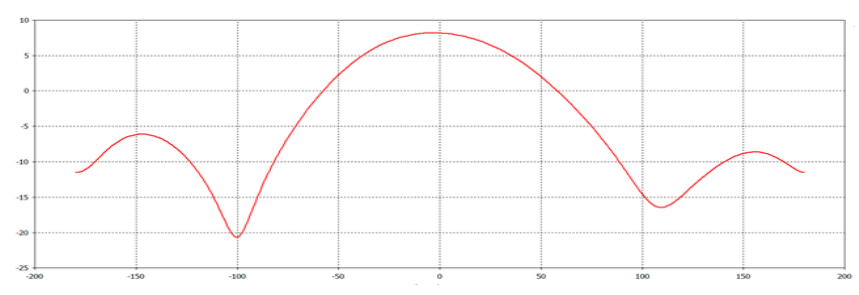

Fig. 5. Polar patternon F1 frequency.

According to the obtained calculations, a prototype of the emitting module was made and its characteristics were researched.

Fig. 6 shows a graph of the SWR versus the frequency of the emitting module prototype in the range from 5 to $9 \mathrm{GHz}$, obtained using a vector analyzer.

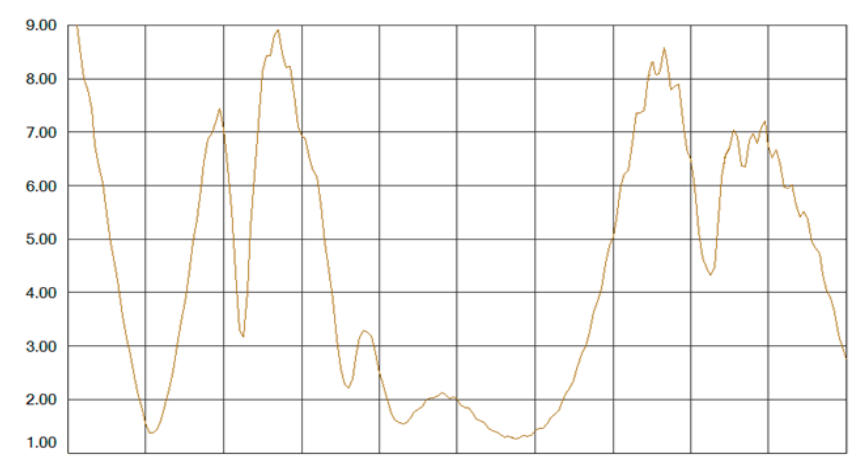

Fig. 6. The graph of $S W R$ versus the frequency of the emitting module prototype in the range from 5 to $9 \mathrm{GH}$.

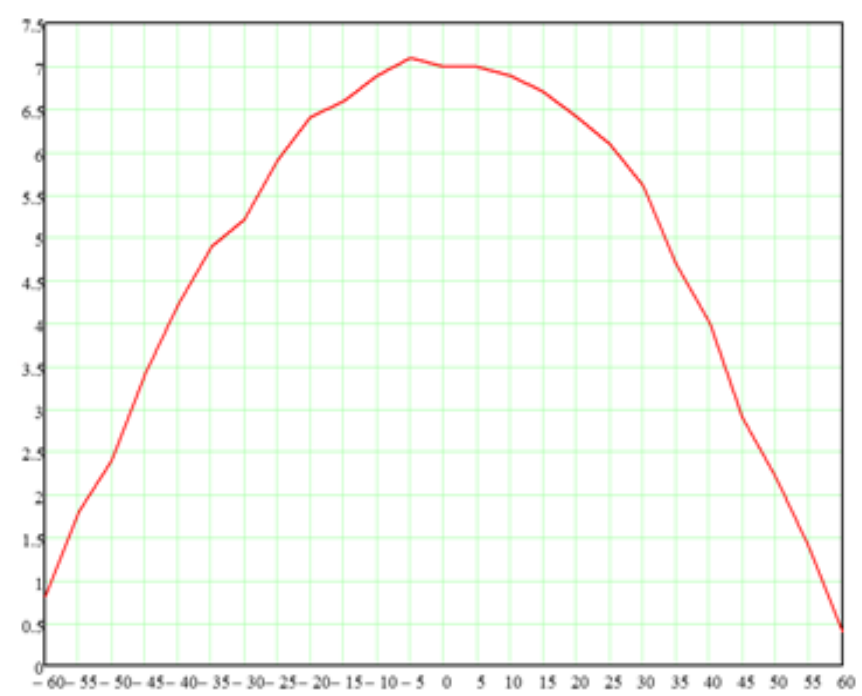

Fig. 7. Polar pattern of the prototype.

Fig. 7 shows the polar pattern, built by support-rotating device, measuring the prototype by reference horn by rotating the emitting module in azimuth in the range from $-60^{\circ}$ to $60^{\circ}$ with step $5^{\circ}$.

From Fig. 8 we can find the width of the polar pattern (at the level of $-3 \mathrm{~dB}$ ) equal to $79^{\circ}$. Using the method of substitution, we measured the gain constant at the F1 frequency equal to $7.1 \mathrm{~dB}$.

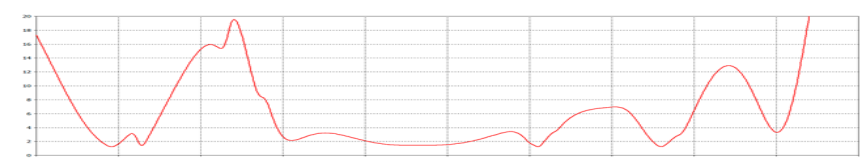

Fig. 8. Graph of SWR versus frequency in the range from 5 to $9 \mathrm{GH}$ \%

\section{COMPARATIVE ANALYSIS}

Considering the results, obtained by measuring the emitting module, significant differences were revealed. After analyzing of the prototype of the emitting module compared with the initial model of the emitting module the adjustments has been made to the model with the aim of approach to a manufactured prototype. In particular, dielectric washers and pins, by which the layers of the emitting module are fixed, have a dielectric constant $\varepsilon=3.2$, which makes misalignment. Recalculating the electrodynamic model taking into account plastic washers and pins, a graph of the SWR versus the frequency (Fig. 8) was obtained. 
Table 1. 6. Balanis CA (Ed.) Modern antenna handbook.

Comparative characteristics of the F1 frequency.

\begin{tabular}{|c|c|c|}
\hline Characteristic & Measured result & Calculated result \\
\hline Gain constant & $7.1 \mathrm{~dB}$ & $8.2 \mathrm{~dB}$ \\
\hline SWR & 1.72 & 1.71 \\
\hline
\end{tabular}

The calculated and measured electrodynamic characteristics of the working area have quite similar values, which are presented in Table 1.

The matching of the second frequency range was disrupted by the high dielectric constant of plastic pins and washers.

\section{CONCLUSION}

As a result, the emitting module was simulated. Manufactured and measured the prototype we have revised the initial model of the emitting module, the appropriate changes were made. As a result of comparison of the specified design characteristics and the results of experimental measurements of electrodynamic characteristics in some aspects, the similarity of the data was revealed. This method of electrodynamic modeling has proved its efficiency. However, the changes have affected on the frequency matching of the second frequency range. The obtained result in the further work in this direction allows to avoid these nuances of matching in the future.

\section{REFERENCES}

1. Genov AA, Macykin SV, Osipov VV, Savilkin SB. The concept of constructing the transmitting path of a multi-beam digital transceivingx-bandAESA. Nauchye trudy (Vestnik MATI), 2015, 26(98):67-73 (inRuss.).

2. Voskresenskij DI. Microwave devices and antennas. Design of phased antenna arrays. Moscow, Radiotekhnika Publ., 2012, 744 p.

3. Panchenko BA, Nefedov EI. Microstrip antennas. Moscow, Radio i svyaz' Publ., 1986, $144 \mathrm{p}$.

4. Obuhovec VA, Kas'yanov AO. Microstrip reflective antenna arrays. Methods of designing and numerical modeling. Moscow, Radiotekhnika Publ., 2006, 239 p.

5. Hansen RC. Phased array antennas. $2^{\text {th }}$ ed. 2009, Hoboken, John Wiley \& Sons, 547 p.
New York, John Wiley \& Sons, 2008, 1680 p.

7. Girish Kumar, Ray KP. Broadband Microstrip Antennas. Norwood, Artech House Publ., 2002, 407 p.

8. Bitaev ES, Obysov AV, Karankevich AA. Research and development of ultra-wideband linear printed antenna array with uniform amplitude-phase distribution. Antenny, 2017, 4:236.

9. Fradin AZ, Ryzhkov EV. Measurement of parameters of antenna-feeder arrangement. Moscow, Svyaz'izdat Publ., 1962, 314 p. 